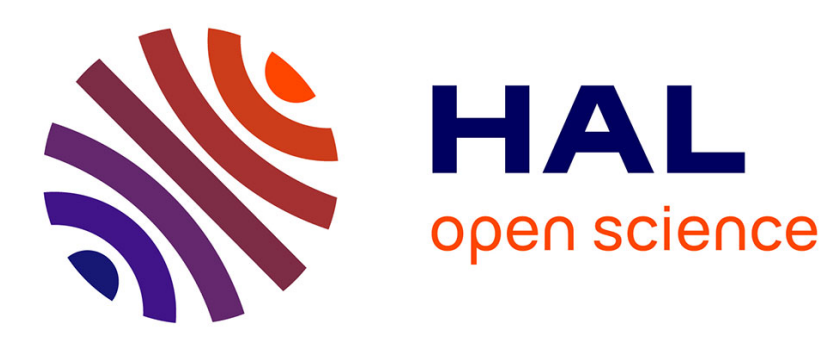

\title{
Can theoretical methods go beyond the experimental data? The case of molecular magnetism.
}

Eduard Cremades, Thomas Cauchy, Joan Cano, Eliseo Ruiz

\section{To cite this version:}

Eduard Cremades, Thomas Cauchy, Joan Cano, Eliseo Ruiz. Can theoretical methods go beyond the experimental data? The case of molecular magnetism.. Dalton Transactions, 2009, 30, pp.5873-8. 10.1039/b902745a . hal-00861581

\section{HAL Id: hal-00861581 \\ https://hal.science/hal-00861581}

Submitted on 16 Sep 2013

HAL is a multi-disciplinary open access archive for the deposit and dissemination of scientific research documents, whether they are published or not. The documents may come from teaching and research institutions in France or abroad, or from public or private research centers.
L'archive ouverte pluridisciplinaire HAL, est destinée au dépôt et à la diffusion de documents scientifiques de niveau recherche, publiés ou non, émanant des établissements d'enseignement et de recherche français ou étrangers, des laboratoires publics ou privés. 


\title{
Can theoretical methods go beyond the experimental data? The case of molecular magnetism $\uparrow$
}

\author{
Eduard Cremades, ${ }^{a}$ Thomas Cauchy,${ }^{c}$ Joan Cano ${ }^{a, b}$ and Eliseo Ruiz ${ }^{* a}$ \\ Received 10th February 2009, Accepted 11th May 2009 \\ First published as an Advance Article on the web 29th May 2009 \\ DOI: 10.1039/b902745a
}

The complexity of polynuclear transition metal complexes with the most appealing magnetic properties makes it impossible to extract the values of exchange interactions between the paramagnetic centers using experimental techniques. Hence, theoretical methods based on density functional theory are used because they allow the accurate estimation of such values. Three $\mathrm{Mn}_{6}$ complexes were studied and the calculated exchange coupling constants used to plot a magnetic susceptibility curve that can be compared with the experimental ones. We propose a new tool to facilitate the understanding of the magnetic properties in systems of this kind. We employed magnetostructural maps to correlate the calculated exchange coupling constants with structural parameters for the dinuclear or polynuclear manganese complexes that we have studied.

\section{Introduction}

The field of molecular magnetism experienced a breakthrough due to the discovery in 1993 of single-molecule magnet (SMM) behaviour by Gatteschi and co-workers in a $\mathrm{Mn}_{12}$ compound. ${ }^{1} \mathrm{~A}$ single molecule of this type behaves like a magnet. Many groups have searched intensively for new polynuclear transition metal complexes showing such an appealing property. ${ }^{2,3}$ Slow relaxation of the magnetization at low temperature is responsible for the presence of a hysteresis loop in magnetization curves, which also display some irregular shapes due to the presence of thermally assisted quantum tunnelling. In order to have slow relaxation of the magnetization, the inversion of the magnetic moment must be hindered by an energy barrier, whose height is known to depend directly on the square of the total spin of the molecule and on its magnetic anisotropy. Such transition metal complexes are much sought after synthetic targets, due to their potential as systems that could eventually lead to applications for future applicability in information storage systems at the molecular level, if the energy barrier is high enough to prevent either the thermal jump or the quantum tunnelling effects. ${ }^{4}$

One crucial point to rationalize the synthesis of such systems is to know the sign and the strength of the exchange interaction constants present in such systems because they control the total spin of the molecule. From an experimental point of view, these parameters are usually obtained by a numerical fit of the measured magnetic susceptibility using a Hamiltonian model. ${ }^{5}$ However, there are two main problems that make it impossible in most

${ }^{a}$ Departament de Química Inorgànica and Institut de Recerca de Química Teòrica i Computacional, Universitat de Barcelona, Diagonal 647, E-08028, Spain.E-mail: eliseo.ruiz@qi.ub.es

' Institució Catalana de Recerca i Estudis Avançats (ICREA), Passeig Lluis Companys 23, E-08010, Barcelona, Spain

'UMR266, Sciences Chimiques de Rennes, Bât 10C, Université de Rennes 1, Campus de Beaulieu, 35042, Rennes, France

$\dagger$ Electronic supplementary information (ESI) available: Additional data. See DOI: $10.1039 /$ b902745a cases to obtain a proper set of exchange coupling constants. The first drawback is related with the memory needed to store the largest block of the Hamiltonian matrix; for example, for a $\mathrm{Mn}_{12}$ complex, thousands of GB of computer memory are required. ${ }^{6}$ Therefore, these computational requirements sometimes prevent to perform the fit. In other cases, when not much memory is needed for instance for the $\mathrm{Mn}_{6}$ complexes studied in this paper (around $0.5 \mathrm{~GB}$ of memory), the presence of many exchange coupling constants and the simple shape of the measured susceptibility curve make it impossible to obtain a single set of exchange coupling constants that fits perfectly with the measured magnetic susceptibility. This second problem has no solution and, hence, theoretical methods can go beyond the experimental techniques to obtain the microscopic description of the exchange interactions present in such polynuclear complexes. From the theoretical point of view, the procedure should consist of a first step, the determination of the exchange coupling constants calculating the energy for different spin distributions using methods based on density functional theory (DFT). ${ }^{6-9}$ The second step must be the verification that these calculated values can reproduce the measured magnetic susceptibility using the exact diagonalisation of the Hamiltonian matrix when the memory requirements are available. For very large systems, approximate methodologies should be used, such as Monte Carlo simulations or other alternative approaches. ${ }^{10}$

In the first part of this manuscript, we will study the magnetic properties of some $\mathrm{Mn}_{6}$ complexes. Recently, Brechin et al. synthesized a large number of $\mathrm{Mn}_{6}$ complexes, and showed that some of these complexes have the largest known energy barrier to the inversion of magnetic moments yet discovered. ${ }^{11-17}$ In the second part of the paper we will introduce a new representation of the correlation between the exchange interaction and structural parameters in di- or polynuclear manganese complexes, the magnetostructural maps. The goal is to extract some conclusions about the sign and strength of the exchange interaction by looking at the number of the bridging ligands and the electronic structure of the cations. 
Table 1 Experimental data corresponding to the family of the $\mathrm{Mn}_{6}$ complexes $\left(\mathbf{1}-\mathbf{1 2},{ }^{12} \mathbf{1 3}-\mathbf{1 5}\right.$, $\left.{ }^{19} \mathbf{1 6}{ }^{20}\right)$, the values of the Mn-N-O-Mn torsion angles and the magnetic data, fitted exchange coupling constants, total spin of the ground state and energy barrier due to the anisotropy of the molecule

\begin{tabular}{|c|c|c|c|c|}
\hline Complex & $\mathrm{Mn}-\mathrm{N}-\mathrm{O}-\mathrm{Mn} /{ }^{\circ}$ & $J / \mathrm{cm}^{-1}$ & $S$ & $U_{\text {eff }} / \mathrm{K}$ \\
\hline$\left[\mathrm{Mn}_{6} \mathrm{O}_{2}(\mathrm{H}-\mathrm{sao})_{6}\left(\mathrm{O}_{2} \mathrm{CH}\right)_{2}(\mathrm{MeOH})_{4}\right](\mathbf{1})$ & $18.0,10.4,25.6$ & $-4.6,-1.8,+1.25$ & 4 & 28 \\
\hline$\left[\mathrm{Mn}_{6} \mathrm{O}_{2}(\mathrm{Me}-\mathrm{saO})_{6}\left(\mathrm{O}_{2} \mathrm{CCPh}_{3}\right)_{2}(\mathrm{EtOH})_{4}\right](2)$ & $42.4,25.5,29.7$ & $+1.2,-1.95$ & 4 & 31.7 \\
\hline \multirow[t]{2}{*}[\mathrm{Mn}_{6}\mathrm{O}_{2}(\mathrm{Et}-\mathrm{sao})_{6}(\mathrm{O}_{2}\mathrm{CCMe}_{3})_{2}(\mathrm{EtOH})_{5}]{$(3)$} & $42.1,36.9,23.3$ & $+1.39,-1.92$ & 6 & 30 \\
\hline & $42.2,16.7,32.4$ & & & \\
\hline$\left[\mathrm{Mn}_{6} \mathrm{O}_{2}(\mathrm{Et}-\mathrm{sao})_{6}\left(\mathrm{O}_{2} \mathrm{CPh}^{2} \mathrm{OPh}\right)_{2}(\mathrm{EtOH})_{4}\right](4)$ & $47.6,23.7,31.8$ & $+1.76,-1.92$ & 7 & 43.2 \\
\hline$\left[\mathrm{Mn}_{6} \mathrm{O}_{2}(\mathrm{Et}-\mathrm{sao})_{6}\left(\mathrm{O}_{2} \mathrm{CPh}^{4} \mathrm{OPh}\right)_{2}(\mathrm{EtOH})_{4}\left(\mathrm{H}_{2} \mathrm{O}\right)_{2}\right](\mathbf{5})$ & $43.7,38.3,30.3$ & $+1.39,-0.99$ & 9 & 56.9 \\
\hline$\left[\mathrm{Mn}_{6} \mathrm{O}_{2}(\mathrm{Me}-\mathrm{saO})_{6}\left(\mathrm{O}_{2} \mathrm{CPhBr}\right)_{2}(\mathrm{EtOH})_{6}\right](\mathbf{6})$ & $42.9,31.9,30.4$ & $+1.15,-0.73$ & 11 & 50.2 \\
\hline$\left[\mathrm{Mn}_{6} \mathrm{O}_{2}(\text { Et-sao })_{6}\left(\mathrm{O}_{2} \mathrm{CPh}\right)_{2}(\mathrm{EtOH})_{4}\left(\mathrm{H}_{2} \mathrm{O}\right)_{2}\right](7)$ & $39.9,38.2,31.3$ & +0.93 & 12 & 53.1 \\
\hline$\left[\mathrm{Mn}_{6} \mathrm{O}_{2}(\text { Et-sao })_{6}\left\{\mathrm{O}_{2} \mathrm{CPh}(\mathrm{Me})_{2}\right\}_{2}(\mathrm{EtOH})_{6}\right](\mathbf{8})$ & $43.1,39.1,34.9$ & +1.63 & 12 & 86.4 \\
\hline$\left[\mathrm{Mn}_{6} \mathrm{O}_{2}(\text { Et-sao })_{6}\left(\mathrm{O}_{2} \mathrm{C}_{11} \mathrm{H}_{15}\right)_{2}(\mathrm{EtOH})_{6}\right](9)$ & $42.6,36.7,34.0$ & +1.60 & 12 & 79.9 \\
\hline$\left[\mathrm{Mn}_{6} \mathrm{O}_{2}(\mathrm{Me}-\mathrm{saO})_{6}\left(\mathrm{O}_{2} \mathrm{C}-\mathrm{th}\right)_{2}(\mathrm{EtOH})_{4}\left(\mathrm{H}_{2} \mathrm{O}\right)_{2}\right](\mathbf{1 0})$ & $31.1,36.3,27.4$ & N/A & $\mathrm{N} / \mathrm{A}$ & $\mathrm{N} / \mathrm{A}$ \\
\hline$\left[\mathrm{Mn}_{6} \mathrm{O}_{2}(\mathrm{Et}-\mathrm{saO})_{6}\left(\mathrm{O}_{2} \mathrm{CPhMe}\right)_{2}(\mathrm{EtOH})_{4}\left(\mathrm{H}_{2} \mathrm{O}\right)_{2}\right](\mathbf{1 1})$ & $47.2,38.2,30.4$ & $+1.85,-0.70$ & 12 & 69.9 \\
\hline$\left[\mathrm{Mn}_{6} \mathrm{O}_{2}(\text { Et-sao })_{6}\left(\mathrm{O}_{2} \mathrm{C}_{12} \mathrm{H}_{17}\right)_{2}(\mathrm{EtOH})_{4}\left(\mathrm{H}_{2} \mathrm{O}\right)_{2}\right](\mathbf{1 2})$ & $41.5,40.1,27.8$ & $+1.55,-2.20$ & $5 \pm 1$ & 31.2 \\
\hline$\left[\mathrm{Mn}_{6} \mathrm{O}_{2}(\text { Et-sao })_{6}\left(\mathrm{O}_{2} \mathrm{CNapth}\right)_{2}(\mathrm{EtOH})_{4}\left(\mathrm{H}_{2} \mathrm{O}\right)_{2}\right](\mathbf{1 3})$ & $41.1,33.3,40.5$ & +1.31 & 12 & 60.1 \\
\hline$\left[\mathrm{Mn}_{6} \mathrm{O}_{2}(\text { Et-sao })_{6}\left(\mathrm{O}_{2} \mathrm{CAnth}\right)_{2}(\mathrm{EtOH})_{4}\left(\mathrm{H}_{2} \mathrm{O}\right)_{2}\right](\mathbf{1 4})$ & $42.3,39.3,25.6$ & $+1.75,-0.90$ & 12 & 60.1 \\
\hline$\left[\mathrm{Mn}_{6} \mathrm{O}_{2}(\mathrm{Et}-\mathrm{sao})_{6}\left(\mathrm{O}_{2} \mathrm{CPhCCH}\right)_{2}(\mathrm{EtOH})_{4}\left(\mathrm{H}_{2} \mathrm{O}\right)_{2}\right](\mathbf{1 5})$ & $38.9,38.7,32.1$ & +0.79 & 12 & 66.8 \\
\hline$\left[\mathrm{Mn}_{6} \mathrm{O}_{2}(\mathrm{H}-\mathrm{sao})_{6}\left(\mathrm{O}_{2} \mathrm{CCH}_{3}\right)_{2}(\mathrm{EtOH})_{4}\right](\mathbf{1 6})$ & $22.8,16.5,10.7$ & $-3.5,-12.6,+12.4,-0.45$ & 4 & 28 \\
\hline
\end{tabular}

\section{Results and discussion}

\section{Exchange coupling constants in $\mathrm{Mn}_{6}$ complexes}

Many SMMs have been synthesized during the last fifteen years, however only recently have some of them shown a higher barrier than the $\mathrm{Mn}_{12}$ complex originally studied. This new family of $\mathrm{Mn}^{\mathrm{III}}{ }_{6}$ complexes with oximato and oxo bridging ligands that were synthesized by Milios et al. showed a wide range of total spin and magnetic anisotropy values (Table 1 ). The total spin values range from $S=4$ for complex 1 to $S=12$, the latter with a total spin expected for a ferromagnetically coupled system with an energy barrier related to a magnetic anisotropy higher than any other SMM (complex 8, see Fig. 1). ${ }^{12}$

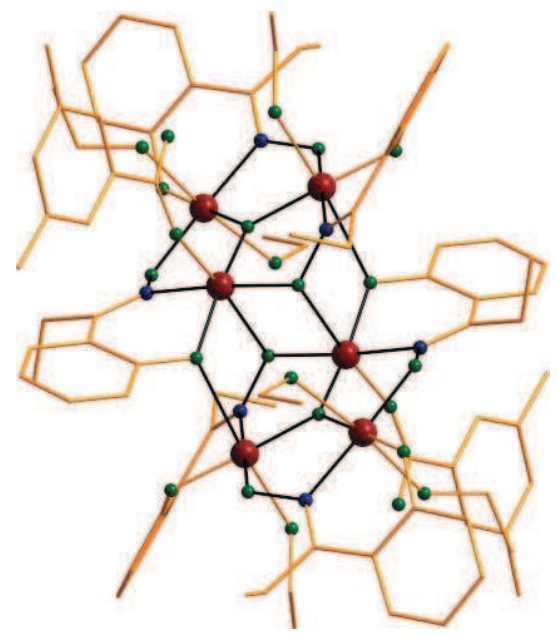

Fig. 1 Representation of the complex 8 (see Table 1) in the crystal structure. Large brown red spheres are the Mn atoms, while oxygen and nitrogen atoms are represented by small green and blue spheres, respectively. The carbon atoms are represented as orange cylinders to simplify the figure.

Recently, we have performed a theoretical analysis of the role of structural parameters for such complexes showing that the distortion of the $\mathrm{Mn}-\mathrm{N}-\mathrm{O}-\mathrm{Mn}$ torsion angle is the key magnetostructural parameter. ${ }^{18}$ Thus, for the Mn-N-O-Mn angle there is a "magic angle" of $30^{\circ}$ : when the angle is larger than this value the coupling is ferromagnetic, when smaller it is antiferromagnetic. The large variety of $\mathrm{Mn}-\mathrm{N}-\mathrm{O}-\mathrm{Mn}$ torsion angles is induced by the presence of an intramolecular hydrogen bond between the substituted salicylaldoxime $\left(\mathrm{saoH}_{2}\right)$ equatorial ligand and the oxygen atom of the bridging ligand, together with the presence of bulky substituents of the axial carboxylato ligands. The presence of ethyl substituents in the sao ligand generally induces a large $\mathrm{Mn}-\mathrm{N}-\mathrm{O}-\mathrm{Mn}$ angle in comparison with hydrogen and methyl groups, due to a hindered intramolecular hydrogen bond (see Chart 1). This hydrogen bond between the ethyl group and the bridging oxygen atom causes an out-of-plane shift of the atom increasing the $\mathrm{Mn}-\mathrm{N}-\mathrm{O}-\mathrm{Mn}$ torsion angle, resulting in ferromagnetic interactions. The role of the out-of-plane shift of the central oxygen atom is relatively less important, but this shift reduces the antiferromagnetic contribution.

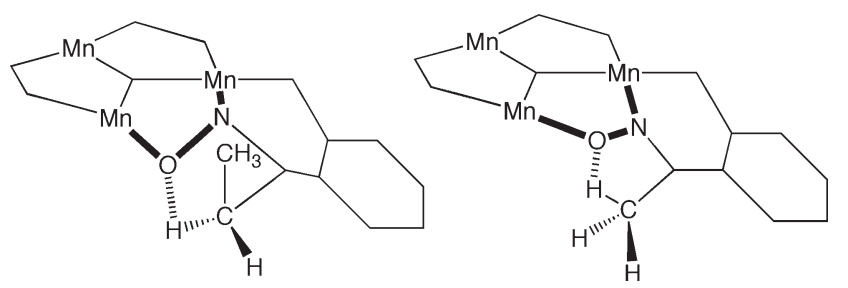

Chart 1

As we have mentioned in the Introduction, one of the problems with these kind of systems with several exchange constants is the existence of many sets of $J$ values that would perfectly fit the measured magnetic susceptibility. Due to such limitations, in some papers the authors prefer to use a reduced set of $J$ values (see Fig. 2 and Table 1) instead of the real set of exchange constants; in this case, for the $\mathrm{Mn}_{6}$ complexes there are five different values (see Fig. 3 and eqn (1) with the exception of complex 3 ). The expression of the Heisenberg-Dirac-Van Vleck Hamiltonian considering only the exchange terms for these $\mathrm{Mn}_{6}$ complexes is the following:

$$
\begin{gathered}
\hat{H}=-2 J_{1}\left[\hat{S}_{1} \hat{S}_{3}+\hat{S}_{4} \hat{S}_{6}\right]-2 J_{2}\left[\hat{S}_{1} \hat{S}_{2}+\hat{S}_{4} \hat{S}_{5}\right]-2 J_{3}\left[\hat{S}_{2} \hat{S}_{3}\right. \\
\left.\left.\left.+\hat{S}_{5} \hat{S}_{6}\right]-2 J_{4}\right] \hat{S}_{3} \hat{S}_{4}+\hat{S}_{1} \hat{S}_{6}\right]-2 J_{5} \hat{S}_{3} \hat{S}_{6}
\end{gathered}
$$



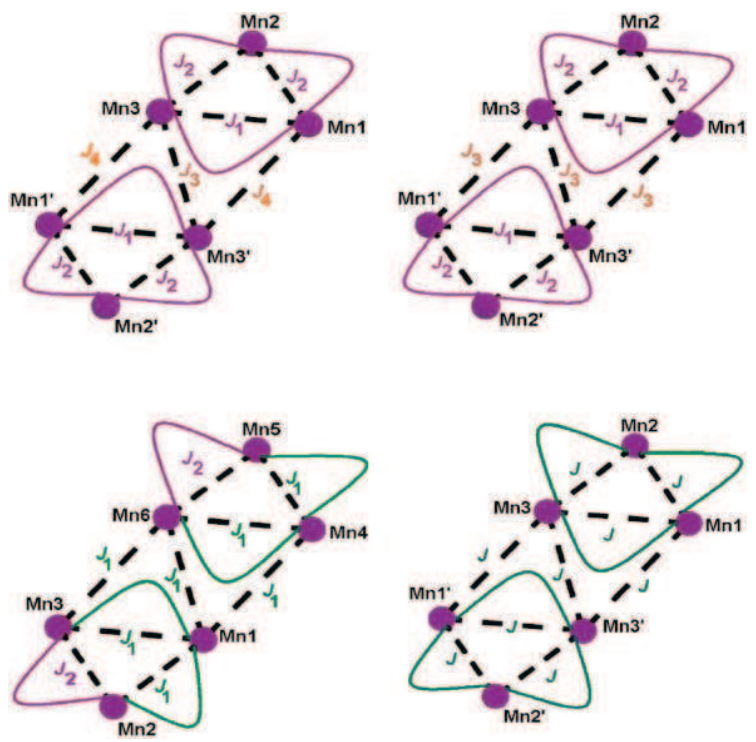

Fig. 2 Description of the $J$ value models used to analyze the experimental magnetic susceptibility data.

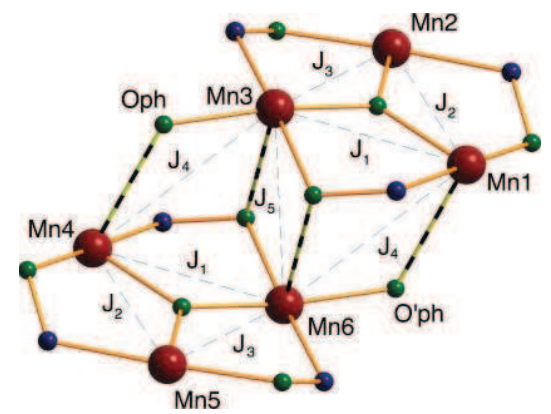

Fig. 3 Description of the $J$ constants used in the theoretical calculations for the symmetric $\mathrm{Mn}_{6}$ complexes. Long interatomic distances due to the Jahn-Teller effect are indicated with the alternate blue-yellow cylinders.

where $\hat{S}_{i}$ is the local spin operator of each paramagnetic centre. Thus, the reduced set of fitted $J$ values corresponds to an average of the complete set of exchange constants. For the non-symmetric complex 3, we have employed the following Hamiltonian:

$$
\begin{gathered}
\hat{H}=-2 J_{1} \hat{S}_{1} \hat{S}_{3}-2 J_{2} \hat{S}_{1} \hat{S}_{2}-2 J_{3} \hat{S}_{2} \hat{S}_{3}-2 J_{4} \hat{S}_{3} \hat{S}_{4}-2 J_{5} \hat{S}_{3} \hat{S}_{6} \\
-2 J_{6} \hat{S}_{1} \hat{S}_{6}-2 J_{7} \hat{S}_{4} \hat{S}_{6}-2 J_{8} \hat{S}_{4} \hat{S}_{5}-2 J_{9} \hat{S}_{5} \hat{S}_{6}
\end{gathered}
$$

In a previous paper, we studied some of the $\mathrm{Mn}_{6}$ complexes; however, there are still unclear points in some complexes that should be analyzed (see Fig. 4), such as the exchange constants of the only non-symmetric complex $(\mathbf{3})^{12}$, the very distorted complex 6 showing a high $S$ value despite the methyl substituents in the sao ligands ${ }^{12}$, and finally, the presence of small $\mathrm{Mn}-\mathrm{N}-\mathrm{O}-\mathrm{Mn}$ torsion angles in complex $\mathbf{1 4}$ with a total spin value of $12 .{ }^{19}$

The calculated $J$ values for the three studied complexes are shown in Table 2. The results for the non-symmetric 3 complex agree perfectly with the "magic angle" recently proposed. ${ }^{18}$ Thus, the two interactions in the triangles with $\mathrm{Mn}-\mathrm{N}-\mathrm{O}-\mathrm{Mn}$ torsion angles smaller than $30^{\circ}$ are antiferromagnetic $\left(J_{3}\right.$ and $\left.J_{8}\right)$, with $J_{8}$ being stronger due to the small torsion angle $\left(16.7^{\circ}\right)$. This complex does not have a large $S$ value despite the presence of an ethyl group in the sao equatorial ligand, which usually results in larger $\mathrm{Mn}-\mathrm{N}-\mathrm{O}-\mathrm{Mn}$ torsion angles due to a intramolecular hydrogen
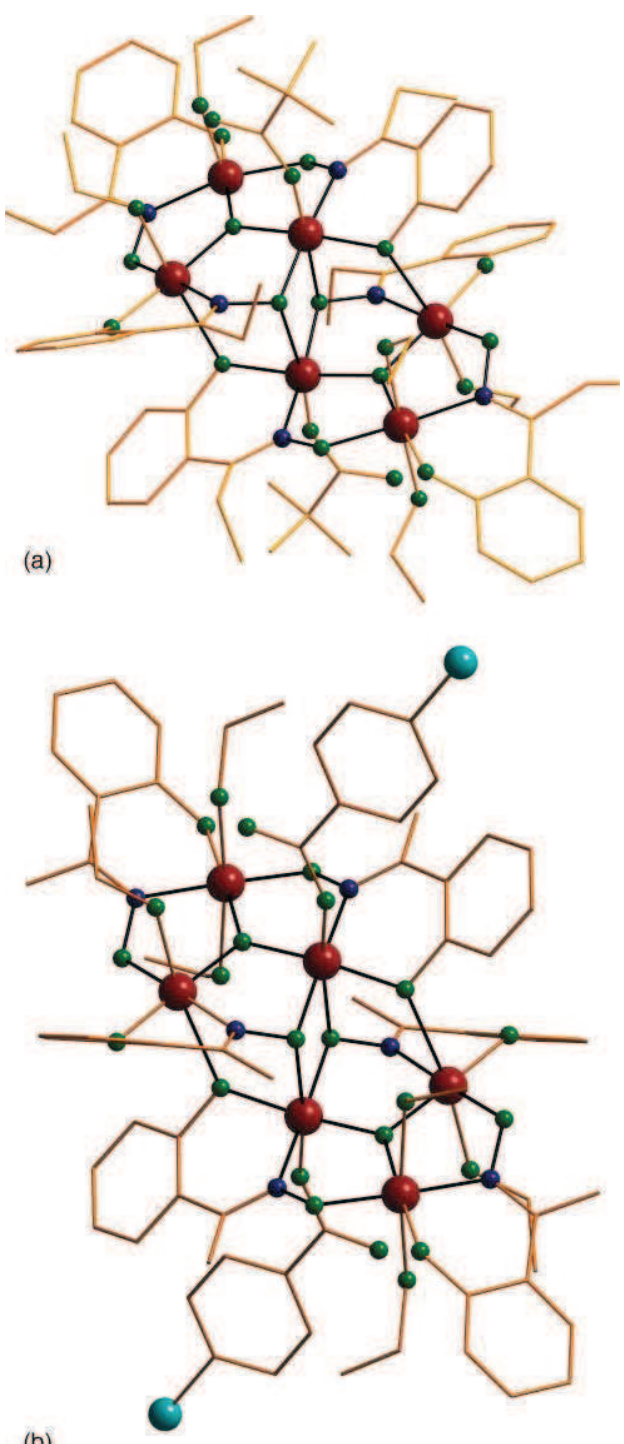

(b)

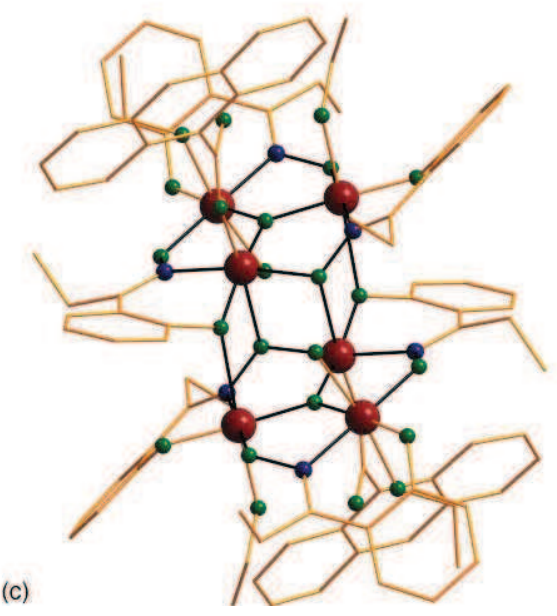

Fig. 4 Representation of the crystal structure, from top to bottom, of the complexes 3, 6 and 14 (see Table 1). Large brown red spheres are the $\mathrm{Mn}$ atoms, while bromine, oxygen and nitrogen atoms are represented by large light blue, small green and blue spheres, respectively. The carbon atoms are represented as orange cylinders to simplify the figure. 
Table 2 Calculated exchange coupling constants $\left(J_{1}-J_{5}\right.$, see Fig. 3 and $J_{1}-J_{9}$ for complex 3$)$ indicating the experimental Mn-N-O-Mn torsion angles corresponding to the $J_{1}-J_{3}$ interactions, and the total spin for the ground and first excited state for the three studied Mn $\mathrm{n}_{6}$ complexes. The value in parenthesis corresponds to the energy difference $\left(\right.$ in $\mathrm{cm}^{-1}$ ) between such states

\begin{tabular}{|c|c|c|c|c|}
\hline Complex & $\mathrm{Mn}-\mathrm{N}-\mathrm{O}-\mathrm{Mn} /{ }^{\circ}$ & $J_{\text {calcd }} / \mathrm{cm}^{-1}$ & $S_{\text {calcd }}$ & $S_{\mathrm{exc}}$ \\
\hline$\left[\mathrm{Mn}_{6} \mathrm{O}_{2}(\text { Et-sao })_{6}\left(\mathrm{O}_{2} \mathrm{CCMe}_{3}\right)_{2}(\mathrm{EtOH})_{5}\right](3)$ & $\begin{array}{l}42.1,36.9,23.3 \\
42.2,16.7,32.4\end{array}$ & $\begin{array}{l}+0.2,+2.0,-0.7 \\
+0.7,+2.1,-0.2 \\
+4.0,-2.8,+0.9\end{array}$ & 0 & $1(0.3)$ \\
\hline$\left[\mathrm{Mn}_{6} \mathrm{O}_{2}(\mathrm{Me}-\mathrm{sao})_{6}\left(\mathrm{O}_{2} \mathrm{CPhBr}\right)_{2}(\mathrm{EtOH})_{6}\right](6)$ & $42.9,31.9,30.4$ & $\begin{array}{l}+2.5,+1.2,+0.7 \\
+1.7,+0.8\end{array}$ & 12 & $11(5.4)$ \\
\hline$\left[\mathrm{Mn}_{6} \mathrm{O}_{2}(\text { Et-sao })_{6}\left(\mathrm{O}_{2} \mathrm{CAnth}\right)_{2}(\mathrm{EtOH})_{4}\left(\mathrm{H}_{2} \mathrm{O}\right)_{2}\right](\mathbf{1 4})$ & $42.3,39.3,25.6$ & $\begin{array}{l}+0.3,+2.1,-0.8 \\
-0.6,+3.5\end{array}$ & 4 & $3(2.1)$ \\
\hline
\end{tabular}

bond. The analysis of the crystal structure indicates that the equatorial sao ligand, due to the repulsion with axial ethanol ligands of the neighbouring molecules, adopts a very flat disposition that induces a small $\mathrm{Mn}-\mathrm{N}-\mathrm{O}-\mathrm{Mn}$ torsion angle. The interactions between the triangles also show the same pattern as in other $\mathrm{Mn}_{6}$ complexes, where the $J_{5}$ interaction is always ferromagnetic while the lateral interactions $\left(J_{4}\right.$ and $\left.J_{6}\right)$ are very small but the sign of the interaction can be positive or negative. For such complexes, the total spin value for the ground state using the calculated $J$ values is zero, and it is different from that determined from the magnetic susceptibility measurements (see Fig. 5). It is worth noting that the first excited states are very close in energy to the ground state due to the weakness of the exchange interactions (see Table 2). Also it is important to remark that in Fig. 5 some differences between curves could be produced for the lack of intermolecular effects and magnetic anisotropy in the curve obtained from the DFT calculated $J$ values. From the experimental point of view, this predicted $S=0$ value also appears in complex 10 (see Table 1), for which the $\chi T$ curve drops to zero at low temperature, but was not fitted because to reach a ground state with $S=0$, the complex must be non-symmetric but the crystal structure of complex $\mathbf{1 0}$ does not fulfil this requirement.

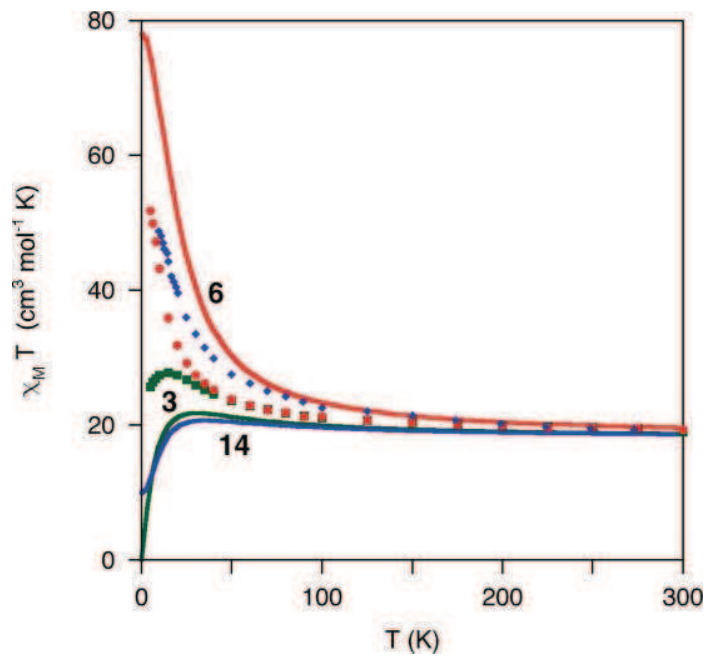

Fig. 5 Representation of the magnetic susceptibility curves corresponding to the three studied $\mathrm{Mn}_{6}$ complexes (see Table 2). The solid lines correspond to the curve obtained from the calculated $J$ values while the dots are the experimental data. ${ }^{12}$

Complex 6 also shows an unexpected behaviour, the opposite of complex $\mathbf{3}$, where with a methyl substituent in the sao ligand the total spin is high $(S=11)$. Again, the results confirm the validity of the "magic angle": all the angles are larger than $30^{\circ}$ and consequently, all the exchange interactions in the triangle are ferromagnetic. Thus, the key question is why the $\mathrm{Mn}-\mathrm{N}-\mathrm{O}-\mathrm{Mn}$ torsion angles are so large for this complex. The crystal structure of this complex shows some peculiarities: the Mn $\cdots$ Mn distance between the two central manganese atoms (Mn3 and Mn6 in Fig. 3) is the largest of all the $\mathrm{Mn}_{6}$ complexes of this family. This long distance between the $\mathrm{Mn}_{3}$ triangles forces the equatorial sao ligand to adopt a non-co-planar arrangement in relation to the $\mathrm{Mn}_{3}$ triangle, which results in a large $\mathrm{Mn}-\mathrm{N}-\mathrm{O}-\mathrm{Mn}$ torsion angle.

For complex 14, the experimental data is confusing. While the ground state has a $S=12$ value, one of the $\mathrm{Mn}-\mathrm{N}-\mathrm{O}-\mathrm{Mn}$ torsion angles is smaller than $30^{\circ}$ (see Table 2). The calculated $J$ values are in agreement with the "magic angle", thus, for the exchange interaction with a small torsion angle, the value is antiferromagnetic. Consequently, the total spin of the ground state is lower than the value obtained experimentally, and the experimental magnetic properties of this system are been reinvestigated because it is the only exception in this family of complexes to this simple and general rule.

\section{Magnetostructural maps}

In this section, we present a new way to show information concerning the magnetic properties for a large set of transition metal complexes. Thus, in Fig. 6 we plot the dependence of the calculated $J$ value on the Mn $\cdots$ Mn distance corresponding to all the di- or polynuclear manganese complexes that we have studied during the last few years (see ESI). $\dagger$ We used the Mn $\cdots$ Mn distance because this parameter allows us to place, in different regions of the map, the exchange interactions that have metals with different oxidation states or a different number of bridging ligands; it is also a general parameter that can be determined for any transition metal complex. The goal of this kind of representation is not just to establish some magnetostructural correlations. The analysis of these figures also allows one to extract some conclusions for a larger group of complexes. In these complexes, the bridging ligands show a large diversity but the alkoxo, hydroxo and oxo bridging ligands are the most frequent ones.

From Fig. 6, we can extract the following conclusions: (i) the $\mathrm{Mn}^{\mathrm{IV}} \cdots \mathrm{Mn}^{\mathrm{IV}}$ interactions (green symbols) show relatively short $\mathrm{Mn} \cdots \mathrm{Mn}$ distances, and the interactions are in practically all cases antiferromagnetic, especially strong when triple bridging ligands are present; (ii) the $\mathrm{Mn}^{\text {III }} \cdots \mathrm{Mn}^{\text {III }}$ interactions (red symbols) are those showing the largest variety in $\mathrm{Mn} \cdots \mathrm{Mn}$ 


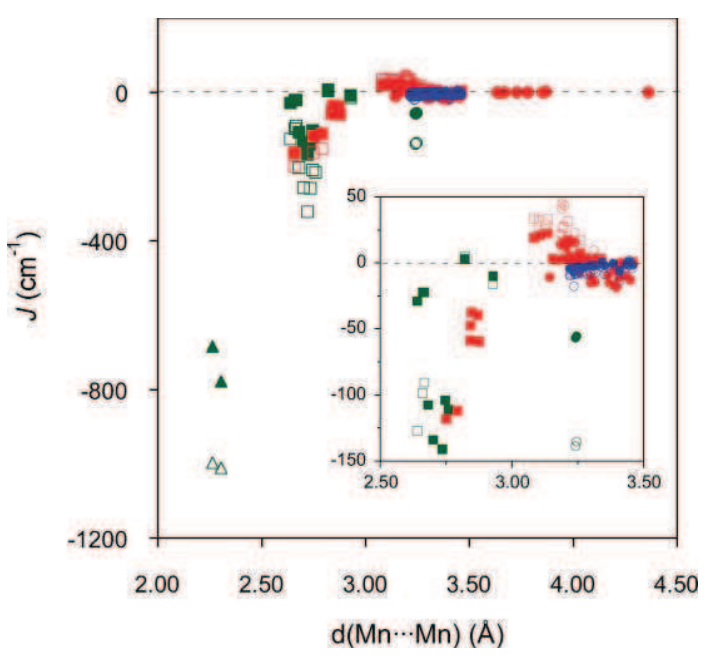

Fig. 6 Magnetostructural maps of the exchange interactions in manganese complexes including an inset for the densest region. Green, red and blue symbols indicate $\mathrm{Mn}^{\mathrm{IV}} \cdots \mathrm{Mn}^{\mathrm{IV}}, \mathrm{Mn}^{\mathrm{III}} \cdots \mathrm{Mn}^{\mathrm{III}}$ and $\mathrm{Mn}^{\mathrm{II}} \cdots \mathrm{Mn}^{\mathrm{II}}$ interactions while triangles, squares and circles correspond to triple, double and single bridging ligands, respectively. Empty and filled symbols indicate if the calculations were performed using GGA numerical calculations (Siesta code) or B3LYP results using Gaussian basis sets (Gaussian and NWChem codes).

distances or in magnetic behaviour. Thus, they can present ferromagnetic or antiferromagnetic interactions with double and single bridging ligands. In the case of single bridging ligands, when the $\mathrm{Mn} \cdots \mathrm{Mn}$ distance is relatively long, the exchange couplings are weakly antiferromagnetic (red circles); (iii) some $\mathrm{Mn}^{\mathrm{III}} \cdots \mathrm{Mn}^{\mathrm{III}}$ interactions through double-bridging ligands are relatively strong antiferromagnetically coupled (red squares in Fig. 6) for short Mn $\cdots$ Mn distances (or small Mn-X-Mn bond angles); (iv) the $\mathrm{Mn}^{\mathrm{II}} \cdots \mathrm{Mn}^{\mathrm{II}}$ interactions (blue symbols) show a large concentration in one region of the magnetostructural map corresponding to very weak interactions that in most cases are antiferromagnetic and (v) from the theoretical point of view, clearly the calculated exchange constants obtained with the Siesta code (empty symbols) overestimate the values in comparison with those obtained with the B3LYP functional and Gaussian functions (Gausian and NWChem codes, filled symbols).

In Fig. 7, we have a similar representation but in this case for mixed-valence manganese complexes. An analysis of it reveals the following conclusions: (i) all the $\mathrm{Mn}^{\mathrm{IV}} \cdots \mathrm{Mn}^{\mathrm{III}}$ interactions (orange symbols) are antiferromagnetic, the strongest ones being those corresponding to double bridging ligands; (ii) the strength of such $\mathrm{Mn}^{\mathrm{IV}} \cdots \mathrm{Mn}^{\mathrm{III}}$ interactions shows a correlation with the Mn $\cdots$ Mn distance, and probably with the $\mathrm{Mn}-\mathrm{X}-\mathrm{Mn}$ bond angle. Thus, shorter $\mathrm{Mn} \cdots \mathrm{Mn}$ distances equal stronger antiferromagnetic interactions; (iii) the $\mathrm{Mn}^{\mathrm{III}} \cdots \mathrm{Mn}^{\mathrm{II}}$ exchange interactions can be weakly ferromagnetic or antiferromagnetic but the ferromagnetism appears only in some complexes with double bridging ligands and (iv) for both Fig. 6 and 7, the results seem to follow a similar trend (and shape); thus, short $\mathrm{Mn} \cdots$ Mn distances correspond to strong antiferromagnetic interactions, an intermediate region around 3-3.5 Å shows moderate antiferromagnetic or ferromagnetic values and finally, for longer distances weak antiferromagnetic coupling is present.

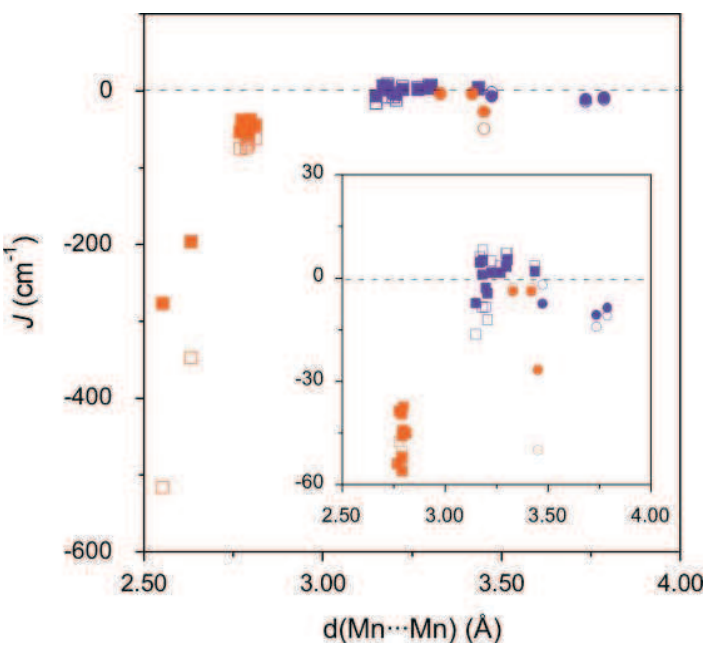

Fig. 7 Magnetostructural maps of the exchange interactions in mixedvalence manganese complexes including an inset for the densest region. Orange and violet symbols indicate $\mathrm{Mn}^{\mathrm{IV}} \cdots \mathrm{Mn}^{\mathrm{III}}$ and $\mathrm{Mn}^{\mathrm{III}} \cdots \mathrm{Mn}^{\mathrm{II}}$ interactions while squares and circles correspond to double and single bridging ligands, respectively. Empty and filled symbols indicate if the calculations were performed using GGA numerical calculations (Siesta code) or B3LYP results using Gaussian basis sets (Gaussian and NWChem codes).

\section{Concluding remarks}

We have used theoretical methods based on density functional theory to study three $\mathrm{Mn}_{6}$ complexes that show unexpected magnetic properties. The calculated $J$ values confirm the "magic value" for the $\mathrm{Mn}-\mathrm{N}-\mathrm{O}-\mathrm{Mn}$ torsion angle that controls the sign of the magnetic interaction; thus, for interactions with a torsion angle smaller than $30^{\circ}$ the coupling is antiferromagnetic, while ferromagnetic values are found for larger angle values. Complex $\mathbf{3}$ is a non-symmetric complex that contains two non-equivalent $\mathrm{Mn}_{3}$ triangles. For this complex, we obtain a $S=0$ ground state in disagreement with the experimental value of $S=6$. The $S=0$ value can be obtained only for non-symmetric complexes; however, this value also appears experimentally for the symmetric complex $\mathbf{1 0}$. In the case of complex $\mathbf{6}$, the coupling is ferromagnetic despite the presence of a methyl substituent in the equatorial ligand, which usually results in antiferromagnetic coupling due to the presence of a small torsion angle. The calculated values indicate that all the interactions are ferromagnetic, as expected from the torsion angle values. The origin of these $\mathrm{Mn}-\mathrm{N}-\mathrm{O}-\mathrm{Mn}$ torsion angles seems to be the presence of the longest distance between the $\mathrm{Mn}_{3}$ triangles of all these $\mathrm{Mn}_{6}$ complexes, which forces the equatorial sao ligand to adopt a non-co-planar arrangement. Complex 14 shows an unexpected highest $S=12$ total spin despite the presence of one small Mn-N-O-Mn torsion angle, and the reported experimental behaviour should be checked again.

Finally, we propose the use of the magnetostructural maps in which we have included all the calculated exchange coupling constants for di- or polynuclear manganese complexes studied by our group during the last few years. These maps are a representation of the correlation between calculated $J$ values and the $\mathrm{Mn} \cdots \mathrm{Mn}$ distance. Thus, it is possible to obtain different regions where similar interactions appear together, and we can 
extract some conclusions about the strength and the sign of the interaction for these kinds of complexes.

\section{Computational details}

In our calculations, we used the experimental structures obtained by X-ray diffraction that take into account small structural effects induced by packing forces that may result in significant changes in the calculated exchange coupling constants, due to the strong dependence of the magnetic properties on structural parameters. ${ }^{21}$ All the calculations of the $\mathrm{Mn}_{6}$ complexes with the B3LYP functional. ${ }^{22}$ were performed with the Gaussian $03 \operatorname{code}^{23}$, and in some cases we employed the NWChem code to check some results. ${ }^{24,25}$ The guess functions were generated with the Jaguar 6.5 code. ${ }^{26}$ The triple- $\zeta$ all electron Gaussian basis set proposed by Schaefer et al. was employed for all the atoms. ${ }^{27}$

In order to obtain the five exchange coupling constants for each $\mathrm{Mn}_{6}$ complex a least-squares fitting using the energies corresponding to nine spin configurations: a high spin solution ( $\left.S_{z}=12\right)$, three $S_{z}=8$ distributions with the inversion of only one spin $\{\mathrm{Mn} 1\},\{\mathrm{Mn} 2\}$ and $\{\mathrm{Mn} 3\}$, three $S_{z}=4$ configurations with negative spin at two $\mathrm{Mn}^{\mathrm{III}}$ cations $\{\mathrm{Mn} 2, \mathrm{Mn} 5\},\{\mathrm{Mn} 1, \mathrm{Mn} 4\}$ and $\{\mathrm{Mn} 3, \mathrm{Mn} 6\}$ (five for the non-symmetrical complex 3, with $\{\mathrm{Mn} 1$, $\mathrm{Mn} 2\}$ and $\{\mathrm{Mn} 3, \mathrm{Mn} 4\}$ ), and finally two $S_{z}=0$ configurations with negative spin at three $\mathrm{Mn}^{\mathrm{III}}$ cations $\{\mathrm{Mn} 1, \mathrm{Mn} 2, \mathrm{Mn} 3\}$ and $\{\mathrm{Mn} 1, \mathrm{Mn} 4, \mathrm{Mn} 5\}$. In the fitting procedure to obtain the five (or nine for complex 3) $J$ values for each $\mathrm{Mn}_{6}$ complex the standard deviations are lower than $0.1 \mathrm{~cm}^{-1}$. The differences between the fitted $J$ values with nine spin configurations and those corresponding to the solvable system of six linear equations using only seven spin configurations are very small, certifying that the obtained set of $J$ values is unique. In order to obtain the energies of the states of the studied molecules, the exact diagonalisation of the Hamiltonian matrix was performed using the MAGPACK code. ${ }^{28}$ From the full spectrum of eigenstates the magnetic susceptibility curves and the $S$ values of ground and excited states were obtained.

\section{Acknowledgements}

The research reported here was supported by the Ministerio de Ciencia e Innovación and Generalitat de Catalunya through grants CTQ2008-06670-C02-01 and 2005SGR-00036, respectively. The authors thankfully acknowledge the computer resources, technical expertise and assistance provided by the Barcelona Supercomputing Center (Centro Nacional de Supercomputación).

\section{References}

1 R. Sessoli, D. Gatteschi, A. Caneshi and M. A. Novak, Nature, 1993, $365,141$.

2 D. Gatteschi and R. Sessoli, Angew. Chem., Int. Ed., 2003, 42, 268.

3 D. Gatteschi, R. Sessoli and J. Villain, Molecular Nanomagnets, Oxford University Press, Oxford, 2006.

4 G. Aromí and E. Brechin, Struct. Bonding, 2006, 122, 1.

5 Magnetism: Molecules to Materialsed. J. S. Miller and M. Drillon, Wiley-VCH, Weinheim, vol. 1-5, 2001-2005.

6 E. Ruiz, S. Alvarez, A. Rodríguez-Fortea, P. Alemany, Y. Pouillon and C. Massobrio, in Magnetism: Molecules to Materials, ed. J. S. Miller and M. Drillon, Wiley-VCH, Weinheim, 2001, vol. 2, p. 227.
7 E. Ruiz, P. Alemany, S. Alvarez and J. Cano, J. Am. Chem. Soc., 1997, 119, 1297.

8 E. Ruiz, S. Alvarez, J. Cano and V. Polo, J. Chem. Phys., 2005, 123, 164110.

9 E. Ruiz, T. Cauchy, J. Cano, R. Costa, J. Tercero and S. Alvarez, J. Am. Chem. Soc., 2008, 130, 7420.

10 E. Ruiz, J. Cano and S. Alvarez, Chem.-Eur. J., 2005, 11, 4767.

11 C. J. Milios, R. Inglis, R. Bagai, W. Wernsdorfer, A. Collins, S. Moggach, S. Parsons, S. P. Perlepes, G. Christou and E. K. Brechin, Chem. Commun., 2007, 3476.

12 C. J. Milios, R. Inglis, A. Vinslava, R. Bagai, W. Wernsdorfer, S. Parsons, S. P. Perlepes, G. Christou and E. K. Brechin, J. Am. Chem. Soc., 2007, 129, 12505.

13 C. J. Milios, M. Manoli, G. Rajaraman, A. Mishra, L. E. Budd, F. White, S. Parsons, W. Wernsdorfer, G. Christou and E. K. Brechin, Inorg. Chem., 2006, 45, 6782.

14 C. J. Milios, S. Piligkos and E. K. Brechin, Dalton Trans., 2008, 1809.

15 C. J. Milios, A. Vinslava, W. Wernsdorfer, S. Moggach, S. Parsons, S. P. Perlepes, G. Christou and E. K. Brechin, J. Am. Chem. Soc., 2007, 129, 2754.

16 C. J. Milios, A. Vinslava, W. Wernsdorfer, A. Prescimone, P. A. Wood, S. Parsons, S. P. Perlepes, G. Christou and E. K. Brechin, J. Am. Chem. Soc., 2007, 129, 6547.

17 C. J. Milios, A. Vinslava, P. A. Wood, S. Parsons, W. Wernsdorfer, G. Christou, S. P. Perlepes and E. K. Brechin, J. Am. Chem. Soc., 2007, 129, 8 .

18 E. Cremades, J. Cano, E. Ruiz, G. Rajaraman, C. J. Milios and E. K. Brechin, Inorg. Chem., 2009, submitted.

19 L. F. Jones, M. E. Cochrane, B. D. Koivisto, D. A. Leigh, S. P. Perlepes, W. Wernsdorfer and E. K. Brechin, Inorg. Chim. Acta, 2008, 361, 3420.

20 C. Milios, C. P. Raptopoulou, A. Terzis, F. Lloret, R. Vicente, S. Perlepes and A. Escuer, Angew. Chem., Int. Ed., 2004, 43, 210.

21 E. Ruiz, J. Cano, S. Alvarez and P. Alemany, J. Comput. Chem., 1999, 20, 1391 .

22 A. D. Becke, J. Chem. Phys., 1993, 98.

23 Gaussian 03: M. J. Frisch, G. W. Trucks, H. B. Schlegel, G. E. Scuseria, M. A. Robb, J. R. Cheeseman, J. A. Montgomery, T. Vreven, K. N. Kudin, J. C. Burant, J. M. Millam, S. S. Iyengar, J. Tomasi, V. Barone, B. Mennucci, M. Cossi, G. Scalmani, N. Rega, G. A. Petersson, H. Nakatsuji, M. Hada, M. Ehara, K. Toyota, R. Fukuda, J. Hasegawa, H. Ishida, T. Nakajima, Y. Honda, O. Kitao, H. Nakai, M. Klene, X. Li, J. E. Knox, H. P. Hratchian, J. B. Cross, C. Adamo, J. Jaramillo, R. Gomperts, R. E. Stratmann, O. Yazyev, A. J. Austin, R. Cammi, C. Pomelli, J. Ochterski, P. Y. Ayala, K. Morokuma, G. A. Voth, P. Salvador, J. J. Dannenberg, V. G. Zakrzewski, S. Dapprich, A. D. Daniels, M. C. Strain, O. Farkas, D. K. Malick, A. D. Rabuck, K Raghavachari, J. B. Foresman, J. V. Ortiz, Q. Cui, A. G. Baboul, S. Clifford, J. Cioslowski, B. B. Stefanov, G. Liu, A. Liashenko, P. Piskorz, I. Komaromi, R. L. Martin, D. J. Fox, T. Keith, M. A. Al-Laham, C. Y. Peng, A. Nanayakkara, M. Challacombe, P. M. W. Gill, B. Johnson, W. Chen, M. W. Wong, C. Gonzalez and J. A. Pople, Gaussian, Inc, Pittsburgh, PA, 2003.

24 NWChem 4.7: E. Aprà, T. L. Windus, T. P. Straatsma, E. J. Bylaska, W. de Jong, S. Hirata, M. Valiev, M. Hackler, L. Pollack, K. Kowalski, R. Harrison, M. Dupuis, D. M. A. Smith, J. Nieplocha, T. V. M. Krishnan, A. A. Auer, E. Brown, G. Cisneros, G. Fann, H. Fruchtl, J. Garza, K. Hirao, R. Kendall, J. Nichols, K. Tsemekhman, K. Wolinski, J. Anchell, D. Bernholdt, P. Borowski, T. Clark, D. Clerc, H. Dachsel, M. Deegan, K. Dyall, D. Elwood, E. Glendening, M. Gutowski, A. Hess, J. Jaffe, B. Johnson, J. Ju, R. Kobayashi, R. Kutteh, Z. Lin, R. Littlefield, X. Long, B. Meng, T. Nakajima, S. Niu, M. Rosing, G. Sandrone, M. Stave, H. Taylor, G. Thomas, J. van Lenthe, A. Wong and Z. Zhang, Richland, Washington 99352-0999, 2005.

25 R. A. Kendall, E. Apra, D. E. Bernholdt, E. J. Bylaska, M. Dupuis, G. I. Fann, R. J. Harrison, J. L. Ju, J. A. Nichols, J. Nieplocha, T. P. Straatsma, T. L. Windus and A. T. Wong, Comput. Phys. Commun., 2000, 128, 260.

26 Jaguar 6.5, Schrödinger Inc., Portland, 2005.

27 A. Schaefer, C. Huber and R. Ahlrichs, J. Chem. Phys., 1994, 100, 5829.

28 J. J. Borrás-Almenar, J. M. Clemente-Juan, E. Coronado and B. S. Tsukerblat, J. Comput. Chem., 2001, 22, 985. 